\title{
¿Y después de la violencia qué queda?
}

\author{
Denis Nohemy Rojas Gómez \\ denisnohemy@gmail.com \\ Universidad de Ciencias Empresariales y Sociales (UCES) \\ Argentina
}

Fecha de recepción: 10/11/2013

Fecha de aprobación: 16/01/2014

\begin{abstract}
Para citar este artículo: Rojas, D. N. (2013). ¿Y después de la violencia qué queda? [reseña del libro ¿Y después de la violencia qué queda? de María Eugenia Ulfe Young]. Ciudad Paz-Ando, 6(2), pp. 172-177
\end{abstract}

Ulfe Young, María Eugenia. ¿Y después de la violencia qué queda? Víctimas, ciudadanos y reparaciones en el contexto post-CVR en el Perú

Buenos Aires: CLACSO, 2013, 94 pp.
- Y después de la violencia qué queda?, es la pregunta de la antropóloga peruana, María Eugenia Ulfe Young, quien a partir de un proceso investigativo en el que busca comprender el post-conflicto peruano, publica en 2013 por CLACSO ¿Y después de la violencia qué queda? Víctimas, ciudadanos y reparaciones en el contexto postCVR en el Perú

El objetivo de esta investigación es estudiar el significado de ser o sentirse víctima en el Perú después del conflicto armado interno. Más que una investigación sobre la condición de víctima en el Perú post Comisión de la Verdad y Reconciliación (CVR) lo que aquí se presenta es una reflexión antropológica sobre ciudadanía, memoria y las políticas de reconocimiento que parten desde las víctimas rurales, campesinas y andinas del conflicto armado interno y cómo estas se encuentran (¿0 desencuentran?) con las políticas públicas que nacen del Estado y que deberían repararlas de forma integral. (Ulfe, 2013, p.12)
El texto de Ulfe, permite plantearse preguntas pertinentes sobre las actuales condiciones en Colombia y lo que desde hace ya varios años viene definiéndose como el post-conflicto. Si bien los diálogos de paz con las FARCEP aparecen como el momento de una posible y deseada transición, estos solo son la punta del iceberg de lo que implica, por un lado, cuestionarse desde la sociedad misma el orden establecido que nos ha llevado a la perpetuación de esta guerra fratricida, y por el otro, imaginarnos y realizar un orden social donde el jnunca más! sea posible.

El texto de Ulfe, es tanto un aporte metodológico, teórico y epistemológico para las ciencias sociales, como un generador de reflexiones para los lectores en general. Desde lo metodológico, plantea la etnografía como técnica de investigación y como producto mismo; en este sentido, el método, el camino del cómo hacer, también es a su vez una llegada, un fin.

El aporte teórico está en considerar el conflicto y el post-conflicto como parte de un entramado social, es decir, como el conjun- 
to de relaciones entre los sujetos en el cual, todo cambio de orden implica un cambio en la construcción y realización de vínculos sociales. Al considerar desde esta perspectiva el análisis, la identidad y la memoria se vuelven conceptos fundamentales.

La autora realiza un aporte epistemológico al exponer abiertamente su perspectiva respecto del lugar del investigador en la sociedad, no solo como investigador, sino también como parte de esa sociedad. Ulfe sitúa el sentido epistemológico en el aspecto metodológico, en el cómo hacer, y expresa que el ejercicio investigativo no es solo un conocer, sino un hacer. Por tanto, en el tratamiento de los datos, la relación con las comunidades, y el uso que se da al conocimiento adquirido, hay un compromiso político del investigador.

\section{La investigación}

La investigación de Ulfe, es un estudio de caso cuya unidad de análisis es la comunidad campesina de Santiago de Lucamarca. La autora toma esta comunidad como caso para el análisis, debido al relato de Envenciana Huancahuari, una mujer campesina víctima de la violencia vivida en Santiago de Lucamarca durante el periodo de lucha armada del Partido Comunista Peruano- Sendero Luminoso (PCP-SL); cuyo testimonio se encuentra en el Centro de Información para la Memoria Colectiva de la Defensoría del Pueblo.

La crudeza de su testimonio, su deseo de justicia y su narración sobre su condición de huérfana, de hija de juramento, de mujer, de viuda, de víctima había despertado en mí esa necesidad de tener que conocerla y recoger su propia voz. Así llegué a Envenciana. Su historia y la de otras personas recogidas en Lucanamarca, Ayacucho y Lima dan vida a esta etnografía. (Ulfe, 2013, p. 12)
Desde este primer momento, Ulfe hace evidente el sentido epistemológico de su investigación y la condición del investigador como sujeto social, no en su función de investigador, sino en su condición de ciudadano, de par, de congénere.

La Comisión de Verdad y Reconciliación (CVR) hace presencia en Santiago de Lucamarca en el año 2002, al reconocer como parte de la agenda de reparación y verdad la masacre perpetrada por el PCP-SL, el 3 de abril de 1983, en donde fueron asesinadas 69 personas entre mujeres, niños y ancianos. Este hecho marcará un punto de quiebre en los procesos sociales en la comunidad, y la llegada de la CVR establecerá una nueva forma de relación con el Estado y será factor determinante en los vínculos entre los habitantes.

\section{La etnografía como método y como producto}

Esta etnografía se centra en el sujeto, en sus historias personales, y no así en la dimensión colectiva de la comunidad. ¿Cómo se define la víctima en esas condiciones? ¿Dónde queda el ciudadano? ¿Quién se inscribe en el Registro Único de Víctimas o RUV? ¿Cómo caracteriza el RUV a la víctima del conflicto armado interno? ¿Qué es ser o sentirse víctima en el Perú post-Comisión de la Verdad y Reconciliación, es decir en un periodo de justicia transicional y de entrega de reparaciones o compensaciones por parte del Estado? (Ulfe, 2013, p.12)

Al considerar la etnografía desde el sujeto, Ulfe considera las relaciones sociales que éste establece y por las cuales se construye y es definido. De esta manera, al estudiar una comunidad campesina busca comprender la relación entre sus pobladores y el Estado, tomando como punto de fuga el 
proceso de reparación de víctimas generado a partir de 2002.

Utilizo el concepto de punto de fuga porque considero que es el que mejor describe este trabajo de Ulfe, ya que la consideración de un momento histórico específico en la historia reciente del Perú le sirve no solo para plantearnos las acciones concretas o la imagen específica de tal periodo sino que, como en una pintura, nos plantea varios planos, diferentes momentos de la comunidad y múltiples convergencias en las narraciones. En síntesis, expone un panorama que permite considerar tanto el pasado como las incertidumbres del futuro que rodean a los habitantes de Santiago de Lucamarca y a la investigadora; la incertidumbre propia de la vida y la apuesta clara por la construcción de una sociedad más justa en medio de un paisaje nebuloso que no permite ver el camino a lo lejos, sino solo en la medida que se recorre a tientas.

Ulfe desarrolla una "etnografía multilocal que parte de una comunidad campesina, Santiago de Lucanamarca, y arriba a dos entidades del Estado, el Consejo de Reparaciones, órgano encargado del Registro Único de Víctimas y la Comisión Multisectorial de Alto Nivel (CMAN) encargada de entregar las reparaciones" (Ulfe, 2013, p.12)

Los sujetos de su investigación son las organizaciones locales, las entidades estatales y algunos integrantes de la comunidad, tales como líderes y personas seleccionadas como víctimas por las instituciones estatales.

La investigación se sustentó a partir de fuentes documentales, entrevistas, diarios de campo y las prácticas performaticas y visuales recolectadas durante el trabajo de campo.

Para Ulfe, la etnografía resulta tanto método como producto. Si bien el investigador igual en tanto ser humano y eso implica considerar la metodología no sólo como un proceso práctico sino como un ejercicio ético y político.

...el investigador que hace su trabajo a la distancia; tampoco es aquel que objetivamente deja de cuestionar ciertas acciones. Investigaciones sobre violencia y memoria enfrentan al investigador a la acción, a comprometerse con los sujetos sociales con quienes desarrolla el trabajo. Surge un problema ético y es qué hacer con la información recogida, cómo escribir sobre ella, ¿cómo escribir sobre vivencias personales que son tan complejas que muestran precisamente las zonas grises de un conflicto armado interno lleno de vaivenes, donde las víctimas se vuelven en ciertos momentos en victimarios y dónde el análisis debe dejar de polarizar para priorizar la polifonía de voces disonantes? Aquí se presentan cuestionamientos de orden metodológico: cómo abordar un estudio de violencia y memoria; cómo acercarse al sujeto herido; qué hacer luego con la información. (Ulfe, 2013, p. 21)

\section{Víctimas, memoria e identidad}

La pregunta por el sentido que la palabra víctima tiene tanto para el Estado como para los habitantes de Santiago de Lucamarca, lleva a Ulfe a desarrollar un texto en el que convergen la información histórica y la narración de hechos.

La información histórica y descriptiva del contexto y funcionamiento de las entidades estatales, así como la manera en que desde estos lugares se construyen los hechos y los casos representativos de un momentos histórico, resultan interesantes para comprender cómo esto obedece a entramados de relaciones sociales y disputas de poder donde el 
campo simbólico es un espacio de batalla, y el desarrollo de programas post-conflicto no se centra en definiciones técnicas, sino en definiciones políticas; es decir, en el proyecto de país que se quiere construir y desde lo cual se define lo técnico.

Teniendo en cuenta lo anterior, resulta relevante para Ulfe analizar la historia de las instituciones públicas creadas como parte del post-conflico, e historizar la construcción de la víctima teniendo en cuenta que esta es una categoría que se transforma.

Esta transformación no es estática y uno de los puntos que se observa es que el vocablo y su sentido (la palabra víctima en sí) cambia en el tiempo: durante el tiempo de la violencia política eran considerados "desplazados" y ese era el vocablo utilizado para referirse a este grupo humano por las migraciones masivas que se sucedían desde el campo hacia las ciudades principales. Luego, y con la intención de no "victimizar" a este grupo, durante el periodo de trabajo de la CVR se utilizó el vocablo "afectados" -que sigue vigente, y que además, coadyuvó a construir una gradiente de "afectaciones" que se muestra en las consideraciones de quiénes son o no son víctimas del conflicto armado interno peruano. Y es debido al Programa Integral de Reparaciones que comienza a usarse la palabra "víctima", que viene con una carga subjetiva y marginal muy marcada. Víctima en oposición a un perpetrador, cuando lo que veremos son zonas grises y fronteras que se cruzan. (Ulfe, 2013, p.19)

Así mismo, el relato aparece como la posibilidad de ejercicio del poder de aquellos que históricamente han sido excluidos y despojados de manera sistemática, no sólo de sus derechos, sus bienes y sus seres queridos, sino también de su propia voz, por lo tanto,
Ulfe pone en evidencia el valor del ejercicio expresivo, el testimonio no sólo fue herramienta para la reconstrucción de los hechos, sino para la dignificación de las víctimas, dado que no era posible la recolección de testimonios de cada uno de los habitantes de los pueblos azotados por la violencia, desde la CVR se realizaron audiencias públicas con algunas personas, el peso de ser representante de otros generó la necesidad entre quienes fueron convocados por ser lo más cercanos a la verdad; por tanto, la comprensión del relato no solo implicaba el reconocimiento de hechos sino de los sentidos imbrincados en éstos y en su narración. "

"El testimonio es la representación oral de la experiencia que puede ser individual o representar un "yo" plural, colectivo. Como en toda representación se produce un intersticio, una tensión, algo que permanece incomunicable, inenarrable" "(Ulfe, 2013, p.56)

Las dinámicas propias de la violencia no sólo tienen como resultado afectaciones individuales, también afectan al colectivo en la medida que los lazos sociales son destruidos. Por lo tanto, para Ulfe, la "víctima no es solamente el sufriente que ha perdido un familiar, sino el cuerpo social en su conjunto que queda resquebrajado, así como también las bases del contrato social partidas después de tanta violencia" (Ulfe, 2013, p.14).

Para la investigadora, la definición de víctima se vuelve central, ya que ésta determina procesos identitarios. Por lo tanto, la disputa por su sentido y la manera en como los sujetos se construyen a partir de una determinada definición marca la relación entre los ciudadanos y el Estado.

¿Qué es ser y sentirse víctima? De la manera cómo se mira a la víctima desde las instituciones del Estado, la víctima se convierte en un re- 
zago de la violencia. Es un resto pero que desde su propia marginalidad también se construye como un sujeto que actúa y elabora sus propios discursos e imágenes. Pero son los ciudadanos quienes le "sacan la vuelta" a la agenda de la memoria como reparación simbólica se reduce en el espacio público peruano a monumentos, museos y ceremonias de conmemoración, para a través de esa plataforma y de aquella que les brinda el programa de reparaciones, reposicionarse y encontrar como víctima, en su condición de afectados de la violencia, una forma diferente de acercarse al Estado y acceder, al menos, a algún tipo de beneficio público y ahí el reconocimiento se convierte en una política de identidad. (Ulfe, 2013, p.79-80)

La memoria se articula a los conceptos de víctima e identidad, debido a que las disputas por el reconocimiento comprenden también el espacio simbólico, de tal que la narración es el ejercicio expresivo que permite el reconocimiento de la historia propia. De esta manera la reconstrucción de la memoria de la historia de violencia reciente de Lucarmarca, también están marcada por un proceso llevado a cabo por sus habitantes en busca de recuperar su historicidad, la narración de testimonios ante la CVR se vio acompañada por reclamos de justicia y verdad, así como por acciones simbólicas que permitieron los duelos aplazado, para lo cual se realizaron ceremonias de entierro simbólicas y se elaboraron producciones audiovisuales sobre los hechos acontecidos.

Para Ulfe, es clave reconocer que la definición de víctima tiene implicaciones sociales, étnicas, culturales y políticas. La caracterización de las víctimas hechas por las entidades estatales, establecen perfiles que contienen rasgos étnicos y culturales que se yuxtapo- de reconocimiento identitario de los grupos y personas que desde las entidades estatales se ubican dentro de dicha categoría.

La ubicación de una determinada población bajo la categoría de víctima y el peso simbólico que a ésta le sea atribuido, puede implicar una nueva forma de legitimación del racismo y clasismo de una sociedad, de manera que los procesos de memoria permiten aproximaciones teóricas y de reflexión para comprender los mecanismos de vinculación entre las comunidades y el Estado.

\section{¿Reparación?}

El texto de Ulfe Young nos permite reflexionar acerca de qué es lo que se repara, qué es lo que fue destruido con la violencia, la posibilidad de considerar que en una sociedad capaz de engendrar un conflicto interno, el sentido de aquello que se repara esté dado por un acuerdo tácito o si en medio del debate por cómo encarar el pos-conflicto sea necesario poner en discusión conceptos dados de antemano.

La violencia en Perú y Colombia aparece en un contexto de desigualdades económicas y culturales extremas, donde el Estado no reconoce la condición de ciudadanía la totalidad de sus habitantes, y donde las élites tradicionales han concentrado el ejercicio del gobierno y de los bienes económicos; un contexto en donde además un sector de la población considera que por medio de las armas puede romper dicho orden social, clasista, racista y excluyente. Esta situación produce rupturas en los lazos familiares y afectivos de quienes pierden su vida en medio de la guerra, las capacidades de quienes resultan mutilados, la confianza cuando se ha instaurado el terror y la venganza, la posibilidad de construcción conjunta y la duda del bien común, entre otras. 
¿En posible considerar que la acción armada que pretendía finalizar un orden social injusto, termine destruyendo aquello que le hacía contrapeso? Y, una vez se logre, la victoria militar de un bando o los acuerdos de diálogo, ¿será posible el debate sobre cómo atender el post-conflicto?

Pareciera que el resultado obvio es la reparación; sin embargo, ¿qué es lo que se desea reparar? el lazo social severamente roto, o la injusticia que dio origen al proceso de violencia, o por el contrario, lo que se desea reparar es el orden anterior a la violencia, lo que no implica la superación de las desigualdades, sino el fortalecimiento del statu quo.

El análisis de Ulfe permite considerar el debate respecto a las políticas de restitución y atención a víctimas al analizar su diseño y aplicación, y cómo éstas pueden convertirse no en procesos de efectiva reparación de la ciudadanía negada históricamente sino en la repetición de las lógicas clasistas y racistas que perpetúan la reproducción del orden anterior; es decir, la aparición de nuevas formas administrativas con las mismas relaciones desiguales de poder. 